\title{
Exploration and Practice of the Construction of Geomatics Experiment Teaching Demonstration Center
}

\author{
Feng Han, Shi-Jie Wang \\ Faculty of Geomatics, Lanzhou Jiaotong University, Lanzhou, China \\ E-mail: hanfeng740412@mail.lzjtu.cn,398235998@qq.com
}

\begin{abstract}
Aiming at the problems in the construction of geomatics experimental teaching demonstration center and in face of the development trend of info-engineering surveying, make an active exploration to building a perfect information surveying platform, highlighting the creative\&practical talent training system, conducting extensive foreign cooperation and exchanges in relation, paying attention to the distributing and lead inside and outside the province, etc. Build a perfect multilevel and multidisciplinary information surveying platform. Obtain good effect on improving the ability of innovative and venture, international exchanges, cooperation and distributing.
\end{abstract}

\section{Keywords-Geomatics; Informational surveying;} Demonstration center;Innovative and venture

\section{RESEARCH BACKGROUND}

Strengthening innovative education and cultivating innovative talents are urgent requirements for innovation driven development and innovative country building. The ministry of education made it clear to deepen the education reform of innovation and entrepreneurship in Colleges and Universities. Pay attention to cultivation of innovative talents. Make full use of university science and Technology Park, experiment teaching demonstration center and engineering practice education center, etc. Provide space for college students' entrepreneurship and increase the number of innovation and entrepreneurship college students. Colleges and universities laboratory is the base to cultivate he creative team , to promote the teaching and research and to develop students' personality. It is particularly important to build and make good use of experimental teaching platform, to make up for the lack of traditional teaching and to play the innovation and cultivation function of the laboratory.

Geomatics experimental teaching demonstration center of Lanzhou Jiaotong University is the only provincial experimental teaching platform of surveying and mapping information in Gansu Province. Center construction plays great effect on stimulating students' enthusiasm for innovation, cultivating their interest in learning and improving students' ability of innovation and entrepreneurship.

Surveying and mapping is an both old and young subject which is stepping into a new stage of info-engineering surveying after analogical style and digital style. During the construction process, hold to the development direction of info-engineering surveying and explore actively from building a perfect information surveying platform, highlighting the creative \& practical talent training system, conducting extensive foreign cooperation and exchanges in relation, paying attention to the distributing and lead inside and outside the province, etc. Truly make the center be an important innovative and venture platform for teachers and students, and also an important base for internal and external cooperation and exchanges on surveying..

\section{MAIN IDEAS AND METHODS OF CONSTRUCTION}

Center construction is mainly based on info-engineering surveying experimental platform. Establish a perfect platform management system for laboratory equipment procurement, equipment management and use, etc. Establish a multi-level practice teaching system according to the demand of info-engineering surveying. The system consists of single practice, integrated practice, course design and graduation design, innovative open experiment, knowledge contest, skills identification, field practice and other aspects. Make full use of the comprehensive training base inside and outside the school to train students' basic skills and innovative awareness. Stress cooperation of many units. Strengthen the combination of school training and enterprise practice and the combination of professional training and social demand. Insist on the coordinated development and comprehensive improvement of knowledge, ability and quality.

\section{A. The Construction of Experimental Teaching Platform Oriented to Information Surveying and Mapping}

Pay equal attention to inheritance and innovation. Introduce new technology, new equipment and update the experimental teaching content on the basis of the inheritance of history. Solve the contradiction between the teacher and students' innovation demand and the obsolete and backward technology of the experimental platform

1) Historical heritage - surveying and mapping history information platform

Make full use of the accumulation of surveying and mapping for 58 years. Collate and collect old surveying and mapping instruments and historical records. Build surveying and mapping instrument museum to display the development history of surveying and mapping instruments and map the history of surveying and mapping and the development of surveying and mapping discipline in our school. Mainly through the guidance of college students to visit and study, build a surveying and mapping history information platform. The vision is to make the museum into the surveying and mapping education base of Gansu province. 
2) Construction of new platform for info-engineering surveying experiment-New technology application and development platform

Combined with the development trend of infoengineering surveying and school equipment purchase plan, prove the equipment purchase plan scientifically and make full use of the existing and new equipment. Build new platform for info-engineering surveying including GNSSCORS station, digital photogrammetry system DPS, measuring robot, unmanned aerial vehicle remote sensing, ground object spectrometer, etc. Cultivate students' sense of innovation and enthusiasm.

Relying on the construction of all kinds of platforms for info-engineering surveying, plan to increase more than 20 innovation experiments and open experiments. Provide the teachers and students new mapping technology application and development platform.

\section{B. Take the Construction of Experimental Platform as an Opportunity to Cultivate Students' Innovative Spirit and Enthusiasm}

The innovative ability training method and mode are relatively weak in the process of practice teaching, explore and solve this problem and make full use of subject competition to stimulate students' innovation spirit and innovation enthusiasm. Organize and guide students to take part in all kinds of discipline competition at all kinds of levels. Play the demonstration and lead role of the subject contest. Lead more and more college students to participate in innovation. Combined with the construction of the experimental platform, build a multi-level, full range of disciplines and skills competition system. Explore the means, methods and modes of cultivating innovative ability.

\section{Explore the Relationship of Experimental Platform Construction, the Innovation Ability of College Students and Improvement of Practical Teaching Level}

Take the construction of experimental platform as an opportunity to explore the relationship of platform construction-innovation ability training-teacher's practical teaching level improvement. Build mutual promotion model. Strive to improve info-engineering surveying experiment platform continuously in order to play the biggest role.

\section{Enhance the Leading Role of Provincial Geomatics Information Experimental Teaching Demonstration Center}

As the provincial mapping and geographic information demonstration center and relying on the only faculty of geomatics in Gansu Province, in the process of construction actively carry out a wide range of domestic and international academic exchange activities. Actively organize provincial competitions and various kinds of new technology applications and other activities to attract college teachers and students to come to exchange. Strive to build the cooperation and exchange base for other universities and companies.

\section{MAJOR CONSTRUCTION ACHIEVEMENTS}

\section{A. Platform Construction Achievements}

According to the school's equipment purchase plan, scientifically demonstrate equipment procurement plan and make full use of existing and new equipment. Develop and improve the information mapping experimental platform. Add open experiment and innovation experiment. At the same time build the surveying and mapping instruments museum. Since 2012, bulid the DPS,GNSS-CORS, Surveying robot, unmanned aerial vehicle remote sensing, three-dimensional laser scanning and other information surveying and mapping experimental platform and the only museum of surveying and mapping in Gansu Province one after another.

Combined with new technology development, developed GPS measurement comprehensive practice based on LZCORS reference station, high speed railway CP III measurement data simulation system, data processing system, application of UAV mapping and virtual reality technology in practical teaching, three dimensional laser scanning technology and its application, analysis of the application of ground object spectrometer and GIS skill practice, etc.

Build a sound multi-level and multi discipline information mapping experimental teaching platform to ensure that the teaching content closely followed by the latest trend of mapping and geographic information industry.

\section{B. Practical Innovation Ability Training}

Practical innovation ability training is mainly through improvement of the experimental project, subject competition support, innovative experimental project, experimental teaching reform support, etc. As an important means to improve students' creative thinking and practical ability and based on the info-engineering surveying platform, establish multi disciplines, integrated and multi level contest system covering mapping, land letters and remote sensing. Take participating in the first level national competitions, organizing and participating in the second level of the provincial competition and improving the normalization of the third level of university teaching competition as guidance, build a multi level and full range of subjects' competition system. Actively organize students to participate in various national, provincial and university academic competitions. Constantly improve the ability of creative thinking by taking part in the "Zetai Cup National College Students Science and technology of surveying and mapping contest" "the GIS skills competition of Chinese universities"," Surveying and mapping skills competition of Chinese college students" and $"$ the ESRI cup Chinese college students GIS software developing competition ". Engineering survey competition which has been held for 21 sessions attractes a large number of students to participate and become a college characteristic competition of high quality. Since 2015 surveying and mapping skills tournament is held in Gansu Province which push the participation of the competition and the organization level to a new level.

In recently 5 years, add more than 30 experimental projects of different kinds, including 15 open, 
comprehensive and innovative experiment projects which do good to 15 majors. Students are organized to participate in national surveying and mapping geographic information innovation competition. Win the first prize of the national level 3 times, second prize 2 times, third prize 13 times, award of excellence 2 times, the provincial competition grand prize 4 times and second prize 1time. Participate in 30 university students innovative experimental projects and win the first prize 1 time, second prize 2 times, third prize 5 times. Especially in the annual meeting of the national Beidou navigation, 2 students who win the national first prize received a cordial meeting of academicians, which is highly recognized of practical ability training of students in our school.

At the same time, encourage professional teachers to participate in the construction of experimental platform actively. Use information mapping platform to undertake some open and innovative experimental projects and improve the professional literacy. Create good atmosphere of interaction between teaching and research and promotion between teaching and experiment. Make teachers form the new teaching concept of teaching of practice participating, summarizing scientifically, and application teaching. Enhance the ability of innovation and practice of teachers and students. Form good circulation mechanism of platform construction - innovation ability cultivation - teachers' practical teaching level improvement.

\section{Carry out Foreign Cooperation and Exchanges}

In the process of construction, focus on the concept penetration to info-engineering surveying particularly. Hold extensive cooperation and exchanges with foreign countries. Invite a number of academicians, Changjiang Scholars, thousands of people plan and well-known experts \& scholars to give speeches at the "National Conference on Traffic Engineering Measurement ". Introduce the new technology of surveying and mapping geographic information to teachers and students. Broaden the horizon of knowledge.

At the same time, establish good cooperation and build a platform with the Chinese Academy of Surveying and Mapping, Geographic Information Bureau of Gansu Province, Surveying and Mapping Science Research Institute of Lanzhou, Gansu Provincial Bureau of Geology and Mineral Resources, the people's Liberation Army and Zhong Haida, Nanfang Surveying, SuperMap, ESRI and other units. Complete 9 practice base and 3 laboratories. Combine student, school, army and company organically. Make full use of the social resources. The students have been trained in engineering practice to cultivate students' engineering consciousness.

Our students have participated in a lot of practices, including high speed railway network CP I and CP II retest $\&$ encryption, precise leveling surveying, line engineering settlement and deformation observation, track accurate adjustment of CP III control network, long tunnel, large bridges independent construction control network design and surveying, deformation monitoring, construction lofting, engineering design changes, class II railway initial test and determination, reconstruction measurement of station, railway finish construction survey, the geographic conditions census, land ownership in rural areas, etc.

During the process play the leading role of the center of the demonstration, continue to expand the impact of the center through the organization to carry out all kinds of new technology seminar, new equipment display, surveying and mapping skills competition of universities and colleges in Gansu Province, holding the seventh session of the national traffic engineering survey academic conferences and other activities. Play radiation and driving function of the provincial demonstration center.

This center has become the preferred cooperation unit of SuperMap, ESRI, Nanfang, Zhong Haida of Gansu, Qinghai and Ningxia provinces. Host various academic competitions and equipment display activities. Especially the indoor positioning of Zhong Haida, Nanfang data factory and 3D laser scanning technology Leica company attracte a large number of teachers and students in the province to come to exchange ideas. The center has become the preferred base of Gansu, Qinghai and Ningxia provinces of surveying \& mapping and geographic information industry exchanges and cooperation.

\section{POPULARIZATION AND APPLICATION EFFECT OF THE RESULT}

\section{A. Information Surveying and Mapping Platform Supports The 15 Major Professional Teaching Practice and Gets Great Achievements in Various Types of Mapping Geographic Information Competition. Play Great Role in Internal and External Radiation.}

At present, there are 15 majors that benefit from the construction of information surveying and mapping platform. Every practical teaching activity is carried out smoothly. Participate in the national provincial competition winning and get rewarded than 30 times. Especially attract the Lanzhou University of technology, Northwest University for nationalities, Gansu Agricultural University, Lanzhou Jiaotong University Bowen College and other universities to participate in the surveying and mapping skills competition, surveying and mapping cultural week, surveying and mapping instrument museum exhibition and other activities. Achieve good radiation and leading role.

\section{B. Relying on the Platform Construction, Teachers and Students Innovation \& Entrepreneurial Ability Has Been Significantly Improved and the New Technology Applications Continue to Expand.}

In the past five years, relying on the development of new technology of surveying and mapping, teachers and students actively participate in the application and development of three-dimensional laser scanning, CORS station applications, unmanned aerial vehicle mapping, terrain analysis ,etc. Support more than 30 undergraduate innovative experiment projects and a number of national and provincial innovation and entrepreneurship projects. Achieve good results, especially in the UAV, three-dimensional laser scanning, navigation and positioning applications, and the Beidou navigation positioning system application, etc. These can be 
used in rail transit construction, information mapping, oil pipeline detection and other fields.

\section{ACKNOWLEDGMENT}

This research was supported by the key educational reform project of Lanzhou Jiaotong University“JGZ2015", "JGZ201608".

\section{REFERENCES}

[1] Liwei Jiang, "Reform of Laboratory Management Systems in Universities", Research and Exploration in Laboratory, vol.31, pp.193-195, 2012.

[2] Lin Tang, Wenbin Wang, Yushuang Luo, "Study of Cultivating Undergraduate Innovative Talents by Using Provincial Key
Disciplines Experimental Platforms", Research and Exploration in Laboratory, vol.35, pp.235-236, 2016.

[3] Jianhua Shen, "Exploration on New Specialized Laboratory Construction Methods under an University-Enterprise Cooperation Mode", Experiment Science \& Technology, vol.15, pp.136-138,2009.

[4] Shijie Wang, Feng Han, Danying Wang, "Construction of Surveying and Mapping Geographic Information Experimental Teaching Platform of Transportation and Civil Engineering College", Mine Surveying,vol12, pp.89-90,94, 2015.

[5] Feng Han, Dexin Yao, "Danying Wang.Engineering Education Accreditation Oriented Construction of the Geomantic Engineering Specialty", vol.24, pp.21-24, 2015.

[6] Lazhen Sun,Zengming Zhang, "Taking Cultivating Students'Ability as Kernel to Set up Multilevel Experiment Course System and Teaching Mode", Experimental Technology and Management, vol.29, pp. 1- 7, 2012. 